\title{
MYCOBACTERIAL LOAD ASSAY
}

\section{Stephen H. Gillespie ${ }^{1}$, Wilber Sabiiti ${ }^{1}$, Katarina Oravcova ${ }^{1}$}

\section{School of Medicine}

University of St Andrews

North Haugh

\section{St Andrews}

\section{Summary}

Tuberculosis is a difficult disease to treat, a process made more difficult as tools to monitor treatment response only provide a result long after the patient has provided a sample. The Mycobacterial load assay (MBLA) provides a simple molecular test to quantify and determine the viability of $M$. tuberculosis in human or other samples.

\section{Introduction}

The Mycobacterial load assay (MBLA) is a culture-free biomarker that aims at providing rapid quantification of viable Mycobacterium tuberculosis in patient sputum. The assay monitors the molecular load of M. tuberculosis (Mtb) cells in sputum samples providing accurate information on bacterial response (decline) to antimicrobial treatment. The bacterial load is determined by detection and quantification of Mtb 16S ribosomal RNA (16S rRNA) using reverse transcriptase realtime quantitative polymerase chain reaction (RT-qPCR). The $16 \mathrm{~S}$ rRNA is a structural RNA occurring in multiple copies in a bacterial cell and its half life and stability is considerably greater in comparison to mRNA. This makes $16 \mathrm{~S}$ rRNA a suitable marker for the detection and quantification of viable bacterial load as it is associated with intact viable cells. When Mtb cells are killed by anti-TB therapy, the amount of $16 \mathrm{~S}$ rRNA also declines making it possible to estimate the number of viable cells remaining in patient sputum. This quantification correlates with viable detection by solid and liquid culture (Mycobacterium Growth Indicator Tube, MGIT) (1, 2). MBLA 
directly quantifies bacterial load in sputum while MGIT gives an indirect measurement based on time to detection (time taken for the sample to flag positive). The higher the bacterial load in patient sputum the shorter the time to positivity (TTP) on MGIT. In comparison to MGIT, MBLA is faster, insensitive to contamination and has the potential to detect non-culturable bacilli (3) (4) MBLA overcomes these inconsistencies in bacterial counts as the assay target, 16S rRNA, is independent of the culturability of the sputum sample.

MBLA is a two-step process consisting of: a) total RNA extraction and enzymatic removal of genomic DNA, b) RT-qPCR and data analysis where cycle threshold (CT) is converted to bacterial load. A cell-based extraction (internal) control is incorporated into the test samples prior to extraction in order to monitor for extraction efficiency and downstream PCR performance. A set of Mtb RNA preparations with known concentrations is amplified along with the test samples to provide a standard curve, a reference for translating $\mathrm{CT}$ values into bacterial load (CFU/ml) in original sputum samples.

Using this methodology it is possible to follow the decline in bacterial load of patients being treated for tuberculosis. Since this is a molecular method, the results are available much more rapidly (within hours) than other methods dependent on culture (Friedrich ref). More importantly, the specificity of the reaction means that a false positive result from contamination is rare whereas this is a considerable cause of data loss for culture based methods.

\section{Materials}

\subsection{Instruments}

1. Laboratory scales

2. Fume hood

3. Fridge $\left(0-8^{\circ} \mathrm{C}\right)$

4. Freezer $\left(-20^{\circ} \mathrm{C}\right)$ 
5. Freezer $\left(-80^{\circ} \mathrm{C}\right)$

6. Vortex, e.g. Genie2

7. Benchtop centrifuge (with sealed removable buckets, for $15 \mathrm{ml}$ plastic tubes), for speeds of $3000 \mathrm{~g}$ for $30 \mathrm{~min}$; e.g. Megafuge 16, Heraeus

8. Refrigerated micro-centrifuge (with sealed removable rotor, for $1.5 \mathrm{ml}$ Microcentrifuge tubes and $2 \mathrm{ml}$ homogenization tubes), e.g. Fresco 21, Heraeus

9. Homogenizer, e.g. Fastprep, MP Biomedical (setting P60, 40 s) or Precellys 24, PeqLab (setting 6000 rpm, 40 s)

10. Thermomixer, with thermoblock for $1.5 \mathrm{ml}$ microtubes, e.g. BLD-455-010C, Microcentrifuge tube

11. QiAgility Pipetting Robot and accessories e.g., QIAgility software, Qiagen plates (5-well master mix plate, 16-well reagent plate, 32-well sample plate, 72-well and 96-well reaction plates)

12. Real-time PCR thermoccycler with accessories e.g., 36-well 72-well and 100well rotors for RotorGene $Q$

\subsection{Additional equipment, consumables and plastic ware:}

1. Pipettes and matching sterile filtered pipette tips, DNAse and RNA-asefree, range: $\mathrm{P} 1000, \mathrm{P} 200, \mathrm{P} 10, \mathrm{P} 2$

2. Sterile Pasteur pipettes, $1.5 \mathrm{ml}, 3 \mathrm{ml}$

3. Disposable gloves, chemical resistant

4. Safety goggles, chemical resistant

5. Biological waste discard jars

6. Chemical waste discard jars

7. $500 \mathrm{ml}$ plastic containers, e.g. $734-5087$, Nalgene

8. Measuring cyllinders, plastic

9. Racks for $1.5 \mathrm{ml}$ and $2 \mathrm{ml}$ microtubes and for $15 \mathrm{ml}$ and $50 \mathrm{ml}$ Falcon tubes, chemical-resistant and autoclavable

10. Sterile disposable universal tubes and $15 \mathrm{ml}$ and $50 \mathrm{ml}$ Falcon tubes

11. Sterile RNA-ase-free microtubes ( $1.5 \mathrm{ml}$ Microcentrifuge tubes), suitable for storing at $-80^{\circ} \mathrm{C}$ 
12. Homogenization tubes, $2 \mathrm{ml}$ with screw caps, compatible with the homogenizer and micro-centrifuge; filled with homogenization beads (0.1 mm glass beads), e.g. MP Biomedicals or 91-PCS-VK01, PeqLab

13. Cooling rack for $0.5,1.5$ and $2 \mathrm{ml}$ micro-tubes or ice bucket

14. PCR reaction tubes suitable for the PCR instrument and the total number of samples to be analyzed. For RotorGene Q (Qiagen) use:

- Single $0.2 \mathrm{ml} \mathrm{PCR}$ optical thin wall flat cap microtubes (any supplier), for a 32-well rotor

- Strips of four tubes and caps, $0.1 \mathrm{ml}$ (Qiagen), for a 72-well rotor

- Rotor-Disc 100 with heat-seal film (Qiagen), for a 100-well rotor

\subsection{Reagents:}

1. Absolute ethanol (99-100\%)

2. TB disinfectant, e.g. Tristel Fuse (freshly prepared or prepared within a week)

3. Molecular grade water, DNase and RNA-ase free, e.g., 13138533, Fisher Scientific

4. Solution to remove RNases from work surfaces and equipment, e.g. RNA-ase Away (Removes RNA-ases enzymes from working space); e.g. 10666421, Fisher Scientific

5. Guanidine thiocyanate (GTC) working solution (200g GTC., $40 \mathrm{~mL} 1 \mathrm{M}$ Trish- $\mathrm{HCl}$ $\mathrm{pH} 7.5,4 \mathrm{~mL} \beta$-mercaptoethanol, $120 \mathrm{~mL}$ molecular grade water (Note 1)

1. $1 \mathrm{M}$ Tris- $\mathrm{HCl} \mathrm{pH} 7.5$

2. $\beta$-Mercaptoethanol

3. Lysing buffer e.g., FastPrep RNAPRO solution or full FASTRNA Pro blue Kit with homogenization beads; MP Biomedicals

4. Chloroform

5. DNA ase e.g., TURBO DNA-free, AM1907M, Invitrogen

6. Positive control: M. bovis BCG (BCG High \& Low concentration) (Note 2).

7. Internal control (MM-IC) (Note 3 and 4)

8. Negative control: Water (Molecular grade RNA-ase free water) (Note 5).

9. Primers and TaqMan probes, $5^{\prime}-3^{\prime}$ sequences are found in the table : 


\begin{tabular}{|l|l|}
\hline Name & Sequence \\
\hline Mtb 16s Forward & GTGATCTGCCCTGCACTTC \\
\hline Mtb 16s Reverse & ATCCCACACCGCTAAAGCG \\
\hline IC MMtmRNA F & CGTCATCCTGGCTAGTTC \\
\hline IC MMtmRNA R & CTACGGCATTCCCTCAAG \\
\hline Mtb 16s probe & FAM-AGGACCACGGGATGCATGTCTTGT-BHQ1 \\
\hline IC MMtmRNA probe & HEX-AGT CCG CTA TGT CTC TGC TCG-BHQ1 \\
\hline
\end{tabular}

Table 1. Identification and sequence of primers used in the MBLA

15. Mastermix suitable for multiplex RT-qPCR e.g., QuantiTect Multiplex RTPCR NR Kit, 204845, Qiagen; described in detail in Table 2

Table 2. Components of the reaction master-mix

\begin{tabular}{|c|c|c|c|c|}
\hline & $\begin{array}{l}\mathrm{RT}+\text { reaction } \\
\mathrm{V} \text { per reaction }\end{array}$ & $\begin{array}{l}X \text { number of } \\
\text { reactions }+8\end{array}$ & $\begin{array}{l}\text { RT- reaction } \\
\text { V per reaction }\end{array}$ & $\begin{array}{l}X \text { number of } \\
\text { reactions }+8\end{array}$ \\
\hline $\begin{array}{l}\text { Quantitect } \\
\text { Mastermix }\end{array}$ & $10 \mu \mathrm{L}$ & & $10 \mu \mathrm{L}$ & \\
\hline $\begin{array}{l}\text { Mtb16S F+ R } \\
\text { primer mix }\end{array}$ & $0.4 \mu \mathrm{L}$ & & $0.4 \mu \mathrm{L}$ & \\
\hline $\begin{array}{l}\text { Mtb16S-FAM } \\
\text { probe }\end{array}$ & $0.2 \mu \mathrm{L}$ & & $0.2 \mu \mathrm{L}$ & \\
\hline $\begin{array}{l}\text { Mm IC tmRNA F+R } \\
\text { primer mix }\end{array}$ & $0.4 \mu \mathrm{L}$ & & $0.4 \mu \mathrm{L}$ & \\
\hline $\begin{array}{l}\text { Mm IC tmRNA } \\
\text { probe }\end{array}$ & $0.2 \mu \mathrm{L}$ & & $0.2 \mu \mathrm{L}$ & \\
\hline RT enzyme & $0.2 \mu \mathrm{L}$ & & ------- & \\
\hline RNA-ase free water & $4.6 \mu \mathrm{L}$ & & $4.8 \mu \mathrm{L}$ & \\
\hline Total volume & $16 \mu l$ & & $16 \mu \mathrm{L}$ & \\
\hline
\end{tabular}

16. $\mathrm{RT}+$, reaction containing reverse transcriptase; $\mathrm{RT}-$, reaction without reverse transcriptase; $V$, volume; $F+R$, forward and reverse primer mixture 
17. Prepare artificial sputum with $400 \mathrm{~mL}$ distilled water, $2.5 \mathrm{~g}$ pig stomach mucin (Sigma), 3.0g diethylene triamine pentacetic acid (DTPA), $2.5 \mathrm{~g}$ sodium chloride, $1.1 \mathrm{~g}$ potassium chloride, $125 \mathrm{mg}$ each of the 20 essential amino acids. $\mathrm{pH}$ is adjusted to 7.0 using $2 \mathrm{M}$ Tris base, water added to $495 \mathrm{~mL}$ and the mixture was autoclaved. After autoclaving $5 \mathrm{~mL}$ egg yolk emulsion is added.

\section{Methods}

\subsection{Sample preservation}

Both patient sputum specimens and BCG positive controls in artificial sputum are preserved in GTC and frozen at $-80^{\circ} \mathrm{C}$ for long term storage or batching purposes.

2. Add $1 \mathrm{ml}$ of homogenized sputum to $4 \mathrm{ml}$ (1:4 ratio) of GTC and freeze at $80^{\circ} \mathrm{C}$ until use.

3. If immediate sample processing is required, mix sputum with GTC at 1:4 ratio, leave for $15 \mathrm{~min}$ at room temperature. Proceed to RNA extraction.

\subsection{Preparation of RT-qPCT mastermix}

1. The mix (QuantiTect Multiplex RT-PCR NR Kit (QT) is supplied in tubes for 200 or $100025-\mu$ l reactions and includes the reverse transcriptase (RT) enzyme. Aliquot the mix by $200 \mu \mathrm{l}$ into $1.5 \mathrm{ml}$ RNA-ase free Micro-centrifuge tube tubes and store at $-20^{\circ} \mathrm{C}$. The RT enzyme can be aliquoted at $100 \mu \mathrm{l}$ and stored at $-20^{\circ} \mathrm{C}$ until use (Note 6).

\subsection{Preparation of primers and probes}


1. Primers and probes are supplied lyophilized and are stable at room temperature $\left(25^{\circ} \mathrm{C}\right)$.

2. Make stock solutions of primers and probes according to the manufacturer's instruction as follows:

a. Dissolve primers in RNA-ase-free molecular grade water to prepare a $100 \mu \mathrm{M}$ stock solution.

b. Dissolve probes in the supplied buffer to prepare a $100 \mu \mathrm{M}$ stock solution. (Note 7).

3. Prepare primer and probe working solutions:

a. Prepare $10 \mu \mathrm{M}$ of forward + reverse primers solution. Aliquot $160 \mu \mathrm{l}$ RNA-ase-free water and add $20 \mu \mathrm{l}$ Forward primer and $20 \mu \mathrm{l}$ reverse primer from stock.

b. Prepare $20 \mu \mathrm{M}$ probe solution, label RNA-ase-free $1.5 \mathrm{ml}$ Microcentrifuge tube tubes with probes names, concentration and the date. Aliquot $80 \mu \mathrm{l}$ RNA-ase-free water and add $20 \mu$ stock probe.

C. Store all working solutions at $-20^{\circ} \mathrm{C}$ until use and protect probes from direct light during use.

\subsection{RNA extraction (Note 8)}

1) Work within a microbiological safety cabinet and clean the working surfaces with a preparation to remove RNA.

2) Thaw on ice all samples, BCG standards and the internal control (IC)

3) Prepare corresponding number of homogenization (containing glass micro beads) tubes and label them according to samples' IDs and controls' numbers both on the tube and on the lid. If you number samples then make record with full reference of the patient ID and corresponding tube numbers.

4) Make sure all tubes with samples and controls are properly labelled (name, control concentration or dilution, and date).

5) Add $100 \mu$ internal control suspension into each sample and standard tube. Pipette directly into the liquid and not on the side of the plastic tube. Mix 
immediately by inverting the tubes. Change pipette tips between the samples.

6) Within the safety cabinet, transfer the tubes into the centrifuge buckets and close the lids.

7) Transfer the buckets to centrifuge and spin at $3000 \mathrm{~g}$ for $30 \mathrm{~min}$. Go to step 10 if you are not working with GTC-preserved samples.

8) After spinning, very gently tip off the GTC supernatant into the corresponding $15 \mathrm{ml}$ tube to be saved at $-80^{\circ} \mathrm{C}$ or discarded into chemical waste. Do not disturb the cell pellet. If the pellet is detached, spin the tubes again.

9) Pipette $950 \mu \mathrm{l}$ of the lysing buffer into each sample tube containing the pellet (aim to use the same pipette tip unless you touch the tube).

10) Suspend the pellet with a P1000 tip in the RNApro solution and transfer the suspension to corresponding homogenization tube.

11) Transfer the tubes into a homogeniser and ensure that the tubes are fully pushed in, that the plastic tube holder is engaged with the metal pin and the spokes are located above each tube. On the FastPrep, screw the cap on the top and then close the lid. (Note 9).

12) Set the FastPrep to programme 6.0 for 40 seconds. For the Precellys 24 , use $40 \mathrm{~s}$ at $6000 \mathrm{rpm}$.

13) After homogenization, centrifuge the tubes for $5 \mathrm{~min}$ at $12,000 \mathrm{~g}$ at room temperature.

14) Leave the tube to stand for 5 minutes following centrifugation.

15) Label fresh $1.5 \mathrm{ml}$ screw cap tubes (RNA-ase free) with the corresponding numbers.

16) Add $300 \mu$ l chloroform into each clean tube

17) From the homogenization tubes, carefully transfer the whole liquid part to the tube containing chloroform using a fine tip pipette (be careful not to transfer bits of sample debris or lysing matrix).

18) Vortex the tubes for $10 \mathrm{~s}$ each

19) Incubate at room temperature for $5 \mathrm{~min}$

20) Centrifuge at $12000 \mathrm{~g}$ at room temperature for $5 \mathrm{~min}$ 
21) Label new $1.5 \mathrm{ml}$ micro-centrifuge tube tubes with the corresponding numbers

22) Carefully transfer the upper aqueous phase to the fresh tubes using $200 \mu \mathrm{l}$ filter tips, being careful not to transfer any of the interphase or lower layer.

23) Add $500 \mu$ l of $100 \%$ ice-cold ethanol to each tube

24) Mix the contents by inverting the tubes 5 times

25) Transfer the tubes containing samples to the $-20^{\circ} \mathrm{C}$ freezer overnight (or to the $-80^{\circ} \mathrm{C}$ freezer for $15 \mathrm{~min}$ if you are doing the whole extraction on the same day). (Note 10)

26) Chill the microfuge to at least $12^{\circ} \mathrm{C}$ prior to centrifugation (set it at $4^{\circ} \mathrm{C}$ ) (Note 11)

27) Centrifuge the samples at $13,000 \mathrm{~g}$ for $20 \mathrm{~min}$

28) Discard the supernatant using a fine tip pipette tip

29) Add $500 \mu \mathrm{l} 70 \%$ ice-cold ethanol to each tube.

30) Centrifuge as above for a further $10 \mathrm{~min}$

31) Discard the supernatant using a Pasteur pipette with fine tip. Use a new pipette for every sample.

32) Dry the RNA at $50^{\circ} \mathrm{C}$ in a heat block (approximately 20-30 min)

33) Dissolve the extracted RNA in $100 \mu \mathrm{l}$ RNA-ase-free water at room temperature for $5 \mathrm{~min}$ and re-suspend the RNA by vortexing for $5 \mathrm{~s}$ Note 12

34) Store the RNA at $-80^{\circ} \mathrm{C}$ or proceed directly to the DNA ase treatment stage. Note 13

\subsection{DNase treatment (Turbo DNA-free kit, Ambion AM1907)}

1) When using Turbo DNA-free kit (Ambion AM1907), prepare a master-mix containing Turbo DNase I 10x buffer and DNase I enzyme for the number of samples (plus two extra to avoid pipetting errors). Per sample, add $10 \mu \mathrm{l}$ buffer and $1 \mu \mathrm{l}$ DNase enzyme to each sample. For example, a 10 sample 
master mix would contain $120 \mu \mathrm{l} 10 \mathrm{x}$ buffer and $12 \mu \mathrm{l}$ of DNase enzymes. (Note 13 and 14)

2) Add $11 \mu$ of DNA-ase-buffer master-mix to each sample (Note 15). Mix by vortexing and then spin briefly (5-10 s at $13000 \mathrm{~g}$ ) to bring everything to the bottom of the tube. This step eliminates droplets hanging on the tube wall and ensures that all RNA extract is in contact with DNase enzyme.

3) Incubate at $37^{\circ} \mathrm{C}$ for $30 \mathrm{~min}$ in the hot-block or incubator

4) After $30 \mathrm{~min}$, add an additional $1 \mu \mathrm{l}$ of DNase enzyme to each tube. Ensure all enzyme goes in by pipetting up and down $x 3$ and then use the tip to stir around and mix the enzyme with the rest of the mixture.

5) Incubate at $37^{\circ} \mathrm{C}$ for a further $30 \mathrm{~min}$ in the hot-block or incubator

6) Thaw the DNase inactivation reagent (white milky substance) 10 min prior to the finish of DNase incubation and keep in the fridge. Re-suspend by vortexing.

7) Add $10 \mu$ l of DNase inactivation reagent into each RNA extract

8) Vortex three times during the 5-minute incubation step at room temperature.

9) After DNA-ase treatment centrifuge at $13,000 \mathrm{~g}$ for $2 \mathrm{~min}$.

10) Label $1.5 \mathrm{ml}$ screw cap tubes with sample ID and extraction date

11) Set your pipette at $110 \mu \mathrm{l}$ and carefully pipette off the RNA to a fresh $1.5 \mathrm{ml}$ RNA-ase free tube without touching any of the inactivation matrix.

12) Store the RNA at $4^{\circ} \mathrm{C}$ until use if performing the RT-qPCR on the same day.

13) For long term use, store the RNA at $-80^{\circ} \mathrm{C}$.

\subsection{Reverse transcriptase - quantitative PCR (RT-qPCR)}

\subsubsection{Samples}

1. Prepare corresponding number of RNA-ase free $1.5 \mathrm{ml}$ micro-centrifuge tube tubes and label them with sample IDs and dates. 
2. Dilute all RNA extracts to be used in a 1 in 10 ratio, i.e. add $10 \mu$ l of RNA extract into $90 \mu$ l of RNA-ase free water. Change tips between samples.

3. Mix well by vortexing for $5 \mathrm{~s}$ and briefly spin down to remove any droplets or air bubbles.

4. For every sample, the RNA is analyzed in duplicate, and both neat and 1 in 10 dilution.

\subsubsection{Preparing standard samples for standard curve}

1. Take the BCG and IC high concentration RNA extracts and thaw on ice.

2. Arrange 7 RNA-ase free tubes for BCG and 7 tubes for IC standards and label them with the appropriate dilution number. Pipette $90 \mu$ l RNAase free water into each tube.

3. Starting with the BCG standards, add $10 \mu \mathrm{l}$ of the extract to the $90 \mu \mathrm{l}$ RNA-ase free water in the first tube. Mix well be vortexing for $5 \mathrm{~s}$. This step creates a 1 in 10 dilution.

4. Transfer $10 \mu \mathrm{l}$ from the first dilution tube into $90 \mu \mathrm{l}$ RNA-ase free water in the second tube. Mix well by vortexing. Repeat this step until you have diluted the RNA extract up to tube 7. Change tips between each dilution each time prior to transferring sample to the next tube.

5. Repeat steps 3 and 4 for IC standards.

\subsubsection{Master mix preparation}

Mastermix is a solution of PCR reagents sufficient for all samples and standards to be amplified. Each RNA sample and its decimal dilution, and standard will be amplified in duplicate. Calculate the master-mix volume taking into account the total number of reactions and including 8 extra reactions to maintain the minimum liquid level when using a pipetting robot to set up the reactions. The composition of master-mix is outlined in Table 2.

1. Use a pipetting robot e.g., the Qiagility to pipette master mix and RNA into PCR reaction tubes. (Note16) 
2. After each use and/or prior to pipetting, decontaminate the pipetting robot and appropriate racks and holders by UV light for $15 \mathrm{~min}$.

3. Defrost the PCR reagents in the clean room.

4. UV decontaminate an aliquot of molecular grade water

5. Instruct the Robot to add $16 \mu \mathrm{l}$ master mix and $4 \mu \mathrm{l}$ sample RNA into the reaction tubes $(0.2 \mathrm{ml}$ thin-walled PCR tubes for 36-well rotor or 4-strip cap tubes for 72-well rotor).

6. Each sample and control should be run in duplicate in RT-qPCR (RT+, containing the RT enzyme) and in a single reaction for master mix without reverse transcriptase (RT-). (Note17 and Note 18).

7. In absence of the robot, use the 72 -well pipetting plate to manually pipette the master mix and RNA (Note 19).

8. Carefully close the lids and transfer the tubes into the corresponding rotor of the RotorGene Q.

\subsubsection{Thermocycler set up using RotorGene Q}

1) When the reaction tubes are in the appropriate rotor, lock them in the position with the locking ring. Place the rotor into RotorGene, click into position and close the lid of the instrument (Note 20).

2) Switch on the RotorGene $Q$ instrument.

3) Switch on the computer and open the RotorGene $Q$ software.

4) Name the operator and write notes defining your assay.

5) Define the reaction volume, $20 \mu \mathrm{L}$

6) Define reaction conditions by clicking on the edit profile button:

a. Hold at $50^{\circ} \mathrm{C}, 30 \mathrm{~min}$ [this is the reverse transcription]

b. Hold at $95^{\circ} \mathrm{C}, 15 \mathrm{~min}$ [this activates the Taq polymerase]

c. Cycling, 40 cycles of: $94^{\circ} \mathrm{C}, 45 \mathrm{~s}$ not acquiring, $60^{\circ} \mathrm{C}, 60 \mathrm{~s}$ acquiring at Green and Yellow (click on the acquiring button to edit fluorescence channels you need for the reaction).

d. Click OK, which takes you back to the summary window.

e. Check the Gain optimization button at first acquisition and leave settings as default. 
f. Click Next which takes you to the summary of reaction conditions.

g. If reaction conditions are correct press the "Start Run" button. You will be asked to save the reaction and after saving the reaction will start and open the sample sheet for sample information input.

h. Complete the sample sheet and click the finish button at the bottom of the sheet. (Note21)

\subsubsection{Result interpretation and qPCR output data analysis}

Careful PCR data interpretation is crucial for correct Mtb bacterial load assessment and treatment monitoring. Amplification data for Mtb samples and BCG and IC controls must be evaluated at all times. Table 3 illustrates how MBLA results are interpreted relative to the internal control:

\begin{tabular}{|c|c|c|}
\hline Target (Mtb/BCG) & IC & Result \\
\hline+ & + & + \\
\hline+ & - & $+^{*}$ \\
\hline- & + & - \\
\hline- & - & invalid \\
\hline
\end{tabular}

+ , positive amplification in RT-qPCR

-, negative amplification in RT-qPCR

*, positive for Mtb but the result cannot be used for quantitative analysis or data normalization as IC was not detected.

Invalid, both target and IC are negative, no amplification detected

\subsubsection{Troubleshooting}

1. If no amplification is detected for the internal control (Yellow channel), ascertain that the internal control was added into the samples by revisiting 
your extraction checklist to confirm that the internal control addition step was performed.

2. Ascertain that your qPCR master mix was correctly composed to include both target (Mtb or BCG) and IC primers and probes.

3. If the answer to 1 and 2 is YES, IC should be positive at least in some of the samples and BCG controls extracted in the same batch.

4. If the answer to 1 is NO, IC will be negative in all samples and BCG controls. Repeat the RNA extraction using sampled spiked with IC.

5. If the answer to 2 is NO, then remake the master mix and repeat the RTqPCR.

\subsection{Construction of standard curves for the MBL Assay}

\subsubsection{Principle}

The Molecular Bacterial Load assay (MBLA) monitors the molecular load of Mtb cells in sputum samples and can provide accurate information on bacterial response (decline) to antimicrobial treatment. The concentration of TB is calculated from $16 \mathrm{~S}$ rRNA present in the sample. The principle of the MBL assay is absolute quantification based on a standard curve consisting of a set of RNA templates with known concentration. The standard curve is used to calculate the Mtb concentration of an unknown clinical sample.

A separate standard curve is used for Mtb quantification and a separate curve is used for the quantification of mycobacterial internal control (IC). Standard curves must be constructed for each real-time PCR instrument, and can be then incorporated into PCR runs and adjusted according to the high and low BCG controls in the run. 


\subsubsection{Standard curves construction}

1. Use RNA extracted from standard material as detailed (Notes 2 and 3), i.e. M. bovis BCG culture and MM-IC cell suspensions with estimated concentrations of $10^{8} \mathrm{CFU} / \mathrm{ml}$ or greater. Work on ice.

2. Prepare $71.5 \mathrm{ml}$ RNase-free tubes and label them with appropriate name and dilution number (e.g. 1 to 7). Dilute the extracted RNA decimally to create a series of standards. Add $10 \mu \mathrm{l}$ of extracted RNA into $90 \mu \mathrm{l}$ of RNase-free water, mix by vortexing for $5 \mathrm{~s}$. Prepare 7 decimal dilutions. Change tips between each dilution.

3. Set up the RT-qPCR mastermixes as outlined above in chapter "RT-qPCR" using appropriate primers and probes combinations.

4. The standards are amplified in duplicates (along with the samples or on their own). Use $4 \mu$ l of RNA dilution and $16 \mu$ l of mastermix per reaction.

5. For each type of RotorGene Q rotor, i.e. 36-well or 72-well, create a separate standard curve. Note: the reaction volume, type of reaction tubes and rotor can influence the PCR performance and fluorescence reading, and hence, cause minor variations in fluorescence signal and the resulting $C_{T}$ values.

6. In RotorGene $Q$ software, label the standards in sample sheet and assign them corresponding concentration and units, e.g. 10E9 copies/ml for the neat BCG RNA, $10 E 8$ for the first 1 in 10 dilution, etc.

\subsubsection{Standard curve data analysis}

A standard curve can be prepared in a separate run for the use with RotorGene $Q$ and it can be further incorporated in data analysis of samples with unknown bacterial load.

1. Analyze the amplification curves in appropriate fluorescence channel, i.e. green channel for Mtb (FAM labelled probe), yellow channel for IC (VIC or HEX labelled probe).

2. Set the fluorescence threshold to 0.01 and examine the curves in exponential view and then in logarithmic mode. Use the same threshold for both Mtb and 
IC channels. Note: the threshold can be set to 0.02 if this improves the efficiency of the reaction.

3. Go to "Analysis" option and select the channel and sample sheet you are going to analyze.

4. Click on "Slope correct" in order to minimize the fluorescence fluctuations.

5. When standards and their respective concentrations are assigned in the sample sheet, the analysis software will automatically populate a standard curve.

6. Examine the parameters of the standard curve. The parameters are:

a. Slope (M), informs on assay efficiency

b. Correlation coefficient $\left(R^{2}\right)$, assesses the standard curve linearity and the dynamic range (or limits of quantification)

c. Intercept, shift in $\mathrm{C}_{\mathrm{T}}$ value on the $\mathrm{y}$ axis

7. The PCR efficiency can be evaluated by the parameters of standard curve. The equation for an ideal standard curve and a $100 \%$ amplification efficiency $(E=1)$ is:

$\mathrm{C}_{\mathrm{T}}=$ slope $\times \log ($ concentration $)-$ intercept

or

$C_{T}=-3.32 \times \log ($ concentration $)-$ intercept

Aim for the efficiency of $90 \%-100 \%$, i.e. $E=0.9$ to 1.0 . The efficiency can be calculated from the slope of the standard curve using the equation:

$E=10^{-1 /-3.32}-1$

8. Very high or too low RNA concentrations in the RT-PCR reaction can cause fluctuations in reverse transcription and subsequent PCR efficiency. These result in outlying $C_{T}$ values. Outlier $C_{T}$ values can be also caused by the errors in pipetting, dilutions' preparation, insufficient homogeneity of a PCR master-mix, evaporation during reaction, improperly placed rotor.

9. Carefully consider removal of the outliers. 


\subsubsection{Importing the standard curve for MBLA analysis}

MBLA is an assay for absolute quantification of an unknown target. Every RNA extraction includes the extraction from high and low BCG positive controls along with the pre-added internal control. The BCG high and low controls contain a known concentration of BCG. Thus the quantification can be adjusted to these samples.

1. In RotorGene $Q$ software, label the BCG high and low controls as standards and assign them appropriate concentration (e.g. $10^{8}$ or $10^{5}$, etc.) and units (copies/ml).

2. When amplification of a series of unknown samples to be analyzed is finished, set the fluorescence threshold to 0.02 (i.e. the same value as the threshold for the standard curves).

3. Select "Slope correct" option.

4. Analyze one channel and one sample sheet at a time, i.e. the amplification in green channel for Mtb samples.

5. In the Analysis mode, select log view of the amplification curves.

6. Click on the amplification curves window. An option for standard curve import will appear in the right hand side of the screen.

7. Import the standard curve from a previous run. Note: make sure you can localize the standard curve run file and that you recognize the quantification parameters, i.e. slope $(M)$, intercept and $R^{2}$.

8. The software now offers you the option of adjusting the reaction efficiency to the current run. The efficiency will be adjusted based on the high and low BCG controls, which you had assigned as standards. Select adjust and continue.

9. The software now automatically populates the standard curve into your current run and calculates the concentrations of the unknown samples. The samples will appear plotted on the standard curve according to their $C_{T}$ values and calculated concentrations. The calculated concentrations and standard deviations for the duplicate samples will appear in the results table. The calculated concentrations are in estimated CFU/ml units (eCFU/ml). 
10. Examine the $C_{T}$ values and calculated concentrations; focus on the standard deviation between duplicate samples. Compare the $C_{T}$ values and calculated concentrations of neat and decimally diluted RNA.

11. If the difference in $C_{T}$ values is around 3.32 or the calculated concentration difference is 10 -fold between the neat and 1 in 10 diluted samples, there was no inhibition of the reaction (usually coming from residual DNase stop solution) and both concentrations of neat and diluted RNA indicate the Mtb concentration in the sample.

12. When calculating the Mtb concentration in the sample, always consider the dilution used for PCR or for the RNA extraction; i.e. multiply the result by 10 for a 10-fold diluted sample.

13. Record the results in appropriate results sheet.

\section{Notes}

Note 1. Preparation of GTC working solution:

Work in the fume cabinet wearing lab coat, gloves and safety goggles. Carefully weigh and transfer $200 \mathrm{~g} \mathrm{GTC}$ powder into the $500 \mathrm{ml}$ plastic container. Measure $120 \mathrm{ml}$ molecular grade water and transfer to $500 \mathrm{ml}$ plastic container containing GTC. Shake thoroughly and then incubate overnight at $37^{\circ} \mathrm{C}$ to dissolve the GTC. You may need to shake again and allow the remaining GTC powder another 30 minutes to dissolve the next day. Add $40 \mathrm{ml} 1 \mathrm{M}$ Tris- $\mathrm{HCl} \mathrm{pH} 7.5$ and adjust the volume to 396 $\mathrm{ml}$ with molecular grade water. When the GTC solution is completely clear, add $4 \mathrm{ml}$ $\beta$-mercaptoethanol and mix well by shaking. Aliquot $4 \mathrm{ml}$ or $8 \mathrm{ml}$ into $15 \mathrm{ml}$ Falcon tubes and freeze immediately at $-80^{\circ} \mathrm{C}$ (Do not leave more than $2 \mathrm{~h}$ on the bench). 


\begin{tabular}{|l|l|}
\hline Reagent & Amounts for $\mathbf{4 0 0} \mathbf{~ m l}$ \\
\hline Guanidine thiocyanate (GTC) & $200 \mathrm{~g}$ \\
\hline $1 \mathrm{M}$ Tris- $\mathrm{HCl} \mathrm{pH} \mathrm{7.5}$ & $40 \mathrm{ml}$ \\
\hline$\beta$-mercaptoethanol & $4 \mathrm{ml}$ \\
\hline Molecular grade water & $120 \mathrm{ml}$ \\
\hline
\end{tabular}

Adding sample to GTC and freezing at $-80^{\circ} \mathrm{C}$ preserves RNA in the sample for a long period of time. This allows sample batching and simplifies sample processing for routine clinical laboratories. GTC also inactivates $M$. tuberculosis reducing risk of infection for the operators.

Note 2. Preparation of M. bovis BCG High and Low Positive controls The positive controls are made from a log phase culture of $M$. bovis BCG (BCG). The culture is prepared by inoculating BCG into $7 \mathrm{H} 9$ medium (with $10 \%$ OADC or ADC growth supplement) and incubating it at $37^{\circ} \mathrm{C}$ for up to three weeks. The bacterial load of positive controls is confirmed by plating on 7H10 agar for CFU counts and qPCR confirmation. Make BCG high (H) positive control by diluting the culture into artificial sputum to a final concentration of $10^{7}$ to $10^{8} \mathrm{CFU} / \mathrm{ml}$ and preserve in GTC at a ratio of $1: 4$, e.g. to a total volume of $5 \mathrm{ml}$ in $15 \mathrm{ml}$ Falcon tubes. Store the controls at $-80^{\circ} \mathrm{C}$ until use. One or two BCG $\mathrm{H}$ controls should be co-extracted in every patient sample RNA extraction batch. The BCG low (L) positive control is made by diluting the BCG culture into artificial sputum to a concentration of $10^{3}$ to $10^{4} \mathrm{CFU} / \mathrm{ml}$ and then preserved in GTC at a ratio of $1: 4$ to a total volume of $5 \mathrm{ml}$ in $15 \mathrm{ml}$ Falcon tubes. Store the controls at $-80^{\circ} \mathrm{C}$ until use. One or two BCG L controls should be coextracted in every patient sample extraction batch.

Note 3. Preparation of the Internal Control (IC)

The Internal (extraction) control is prepared from a log phase of Mycobacterium marinum cultured in $7 \mathrm{H} 9$ medium (without growth supplement ADC or OADC) at $30^{\circ} \mathrm{C}$. Centrifuge a fraction of the culture at $3000 \mathrm{~g}$ for $30 \mathrm{~min}$ (or $10 \mathrm{~min} 10000 \mathrm{~g}$ for 
a benchtop centrifuge), discard the supernatant and freeze the cell pellets at $-80^{\circ} \mathrm{C}$. Use a different fraction of the same $M$. marinum culture to determine its concentration (CFU/ml) by inoculating $7 \mathrm{H} 10$ agar and incubating at $30^{\circ} \mathrm{C}$ for $3-5$ days. Thaw the frozen pellets at room temperature and re-suspend in GTC supplemented with $1 \% \beta$-mercaptoethanol solution to $10^{5} \mathrm{CFU} / \mathrm{ml}$. Store at $-80^{\circ} \mathrm{C}$ for long term use. At the time of sample RNA extraction, spike each sample and BCG positive control with $100 \mu \mathrm{l}$ of the internal control suspension. The final concentration of internal control in the sample should be $10^{4} \mathrm{CFU} / \mathrm{ml}$.

Note 4. It is essential that the internal control is carefully managed as there is a risk of cross-reaction if the concentration of the internal control is greater than $10^{4}$ $\mathrm{CFU} / \mathrm{ml}$.

\section{Note 5. Molecular grade water}

Keep the water sterile at room temperature. To prevent any contamination, it is recommended to aliquot small amounts into RNase free vessels to work with. The water aliquot used for RNA extraction and RT-PCR set-up should be also used as a no template control (NTC) or negative control for PCR.

Note 6. Before setting up a PCR, work out how much QT PCR master-mix needed and take out the exact number of aliquots to use. Avoid multiple freeze-thaw cycles of the QT mix.

Note 7. Store the oligonucleotides at $-20^{\circ} \mathrm{C}$ and protect the probes from direct light by using coloured non-transparent tubes or wrapping the tubes in aluminum foil during use.

Note 8. All procedures must be completed in a microbiological safety cabinet until the organisms are confirmed to be killed. The lysis kills Mtb, and the rest of the extraction can continue in a bio-safety 2 lab. Clean the outsides of all tubes with disinfectant before they are transferred into the bio-safety 2 lab. 
Note 9. FastPrep instrument or alternative bead beater will increase the yield.

Note 10. Sometimes the tube will freeze at $-80^{\circ} \mathrm{C}$ if there is a lot of salt in the sample. Allow to thaw at room temperature, approximately $5 \mathrm{~min}$.

Note 11 Orientate the tubes in the centrifuge so that hinged back of the tube sits on the outside diameter of the rotor. This way you will know where the pellet is sitting when you remove the supernatant.

Note 12 If the reconstituted RNA is viscous and doesn't re-suspend add a further 100 $\mu$ of water.

Note 13 The tube top colours change and so make sure you read the labels of the tubes to ascertain that you are adding right reagent.

Note 14 It might be necessary to add $15 \mu \mathrm{l}$ in tubes where more DNA is anticipated e.g. in baseline samples and BCG high standard.

Note 15. The master mix accounts for $16 \mu \mathrm{l}$ I of the reaction volume. Adding $4 \mu \mathrm{L}$ of sample (RNA extract) makes the total volume of reaction $20 \mu \mathrm{L}$.

Note 16 Manual pipetting can be used if only few samples e.g $\leq 10$ samples are being processed.

Note 17. Once qPCR without any added RT enzyme (RT-) has been done on samples and the result is negative, e.g. there is no DNA present, there is no need to repeat this for subsequent runs of the same samples.

Note 18. The following number of reactions per run can be calculated: 72-well rotor: Samples 20x2 RT+, 20x1 RT-, 2x2 BCG H \& 2x2 BCG L RT+; 1×1 BCG H \& 1x1 BCG L RT, $1 \times 2$ Water (NTC) RT+, 1×1 Water RT- = 71 reactions in total

36-well rotor: Samples 9x2 RT+, 9x1 RT-, 1x2 BCG H \& 1x2 BCG L RT+; 1x1 BCG H \& 1x1 BCG L RT-, 1×2 Water (NTC) RT+, 1×1 Water RT- = 36 reactions in total 
Note 19 All samples and BCG controls are run neat and its 1 in 10 dilution. Standard curve samples don't have to be run every time. The standard curves can be imported from a previous run.

Note 20 Make sure the names in the sample follow the order of the reaction tubes on the rotor.

References

1. I. Honeyborne, T.D. McHugh, P.P.J. Phillips, et al. (2011) Molecular Bacterial Load Assay, a Culture-Free Biomarker for Rapid and Accurate Quantification of Sputum Mycobacterium tuberculosis Bacillary Load during Treatment, 49, 3905-3911.

2. I. Honeyborne, B. Mtafya, P.P.J. Phillips, et al. (2014) The Molecular Bacterial Load Assay replaces solid culture for measuring early bactericidal response to anti-tuberculosis treatment.

3. R. Bowness, M.J. Boeree, R. Aarnoutse, et al. (2014) The relationship between Mycobacterium tuberculosis MGIT time to positivity and cfu in sputum samples demonstrates changing bacterial phenotypes potentially reflecting the impact of chemotherapy on critical sub-populations, Journal of Antimicrobial Chemotherapy. dku415.

4. G.V. Mukamolova, O. Turapov, J. Malkin, et al. (2010) Resuscitationpromoting Factors Reveal an Occult Population of Tubercle Bacilli in Sputum, American journal of respiratory and critical care medicine. 181, 174-180. 